\author{
N.Zh. Omirbekova*, Zh.K. Zhunusbayeva, A.I. Zhussupova \\ School of Biology and Biotechnology, al-Farabi Kazakh National University, Almaty, Kazakhstan \\ *E-mail: Nargul.Omirbekova@kaznu.kz
}

\title{
Induced mutagenesis in obtaining donors of resistance to leaf rust in wheat
}

\begin{abstract}
The Concept of Kazakhstan entrance into one of the 30 most developed countries of the world long-term priorities are designated, one of which is translated into the path of innovation of agricultural industry, development of sustainable and highly productive agriculture. In countries, which are the major producers of marketable grain in the world, the main strategy advocates creation and introduction of wheat varieties resistant to abiotic and biotic environmental factors, namely, creation of productive drought-tolerant, salt-tolerant, and resistant to various diseases varieties with high grain quality.

Keywords: induced mutagenesis, surfactants, resistance.
\end{abstract}

\section{Introduction}

Creation of new wheat varieties is impossible without improving the existing genetic and breeding methods and techniques, one of which is the method of induced mutagenesis. To increase the efficiency of mutation breeding of plants it is necessary to study the conditions and methods of mutagenic effects, allowing to expand the spectra of genetic variation and to increase the yield of useful mutations. For this it is necessary to choose a chemical mutagen compound causing variation with positive effect. One of the representatives of the possible weak mutagens are surfactants $[1,2]$.

One of the most common and harmful diseases of wheat leaf rust is caused by the basidiomycete Puccinia recondita Rob. ex Desm. f. sp. Tritici, leading to reduction of assimilating surface and increased transpiration of plants, and as a result violations in the water balance, causing premature leaf death and reduced winter hardiness. Shortage of grain yield can reach up to $20-30 \%$.

The aim of this research was to study the mutational variability of soft wheat under the influence of surfactant for highly resistant to Puccinia recondita agronomic wheat genotypes and development of scientific and methodological approaches for production of the original forms of wheat to improve the efficiency of selection for adaptability and productivity.

\section{Materials and methods}

The objects of study were the generation of mutant lines $M_{1}$ and $M_{2}$ from 4 varieties of soft wheat of local selection - Kayir, Melturn 490, Kazakhstanskaya early ripe and Shagala, obtained after treatment with various surfactants, which are used in biological research: Triton X-305, Triton X-100, Tween 85, Tween 65, and Tween 20.

To determine the resistance of plants from the mutant forms of wheat $\mathrm{M}_{2}$ generation to brown rust, mutant forms of $M_{1}$ and control varieties of soft wheat Kayir, Kazakhstanskaya early ripe, Melturn 490 and Shagala were seeded on the infectious background of the Kazakh Research Institute of Agriculture and Crop production.

Estimation of resistance on the infectious background was carried out jointly with the staff of the laboratory of plant immunity of the same Institute. Phytopathological evaluation of resistance to leaf rust was performed 8-11 days after inoculation according to the standard procedure [3].

\section{Results and their discussion}

According to the McIntosh R.A. 5 types of reaction exist: 0 - immune, the degree of damage is not observed; R-resistant, the plant is able to resist the action of the pathogen; MR - moderately resistant; MS - moderately susceptible; S - susceptible [4]. 
Results of phytopathological assessment of resistance to the leaf rust of wheat $\mathrm{M}_{2}$ generation mutant forms are presented in Table 1.
As seen from the Table 1, the mutant forms of wheat variety Kayir display the maximum resistance to the leaf rust.

Table 1 - Screening of the wheat $\mathrm{M}_{2}$ generation mutant forms on their resistance to Puccinia recondita

\begin{tabular}{|c|c|c|}
\hline Variety & Treatment of plants with surfactants & Degree of damage \\
\hline \multirow[t]{6}{*}{ Kayir } & Control (without treatment) & $\mathrm{R}$ \\
\hline & Tween 20 & $60 \mathrm{R}$ \\
\hline & Tween 65 & $80 \mathrm{R}$ \\
\hline & Tween 85 & $\mathrm{R}$ \\
\hline & Triton $\mathrm{X}-100$ & $\mathrm{R}$ \\
\hline & Triton $\mathrm{X}-305$ & $\mathrm{R}$ \\
\hline \multirow[t]{6}{*}{ Kazakhstanskaya early ripe } & Control (without treatment) & $60 \mathrm{MR}$ \\
\hline & Tween 20 & $80 \mathrm{MR}$ \\
\hline & Tween 65 & $15 \mathrm{MS}$ \\
\hline & Tween 85 & $50 \mathrm{MR}$ \\
\hline & Triton $\mathrm{X}-100$ & $30 \mathrm{MR}$ \\
\hline & Triton $\mathrm{X}-305$ & $40 \mathrm{MS}$ \\
\hline \multirow[t]{6}{*}{ Melturn 490} & Control (without treatment) & $40 \mathrm{MS}$ \\
\hline & Tween 20 & 70MR \\
\hline & Tween 65 & $80 \mathrm{MR}$ \\
\hline & Tween 85 & $85 \mathrm{MR}$ \\
\hline & Triton $\mathrm{X}-100$ & $30 \mathrm{MR}$ \\
\hline & Triton $\mathrm{X}-305$ & $20 \mathrm{MS}$ \\
\hline \multirow[t]{6}{*}{ Shagala } & Control (without treatment) & MS \\
\hline & Tween 20 & $40 \mathrm{MS}$ \\
\hline & Tween 65 & $30 \mathrm{MS}$ \\
\hline & Tween 85 & 20MR \\
\hline & Triton $\mathrm{X}-100$ & 70MS \\
\hline & Triton X-305 & $60 \mathrm{MS}$ \\
\hline
\end{tabular}

Treatment with surfactants might also increase the resistance to the leaf rust of Shagala and Melturn 490 mutant forms.

It should be noted that the mutant forms of Kayir variety during the primary screening show high resistance, when treated with the various types of surfactants, at the same time as moderate during the secondary screening. The mutant forms of Shagala variety treated with the surfactant Triton X-100 in the primary screening show moderately susceptible type of reaction to leaf rust, in the secondary resistant type of reaction.

Comparative analysis of the results of wheat treatment with surfactants shows that the most effective is treatment with the surfactant Triton
$\mathrm{X}-100$, for the mutant forms of Kazakhstanskaya early ripe and Melturn 490 varieties.

Mutant forms of Kayir variety are highly resistant to the leaf rust with the reaction type of «0» points. Whereas mutants derived on the basis of Melturn 490 and Shagala varieties display an intermediate type of inheritance - with the reaction type of «1-2» points. As a consequence, treatment with surfactants might affect the resistance to the leaf rust.

Results obtained show a definite prospect of chemical mutagenesis in wheat breeding.

Comparison of elements of productivity of Kazakhstanskaya early ripe variety and its experimental variants treated with different 
surfactants shows that the inhibitory effect on the studied quantitative traits is on Triton X-100, while the stimulatory effect is observed on Tween 20. For other variants of the experiment some variability performance characteristics are noted, which are not statistically significant (Table 2).

Table 2 - Elements of productivity of control and mutant forms of the $\mathrm{M}_{2}$ generation of Kazakhstanskaya early ripe and Kayir varieties

\begin{tabular}{|c|c|c|c|c|c|c|c|}
\hline $\begin{array}{l}\text { Variants of } \\
\text { treatment }\end{array}$ & $\begin{array}{c}\text { Tillering, } \\
\text { pcs. }\end{array}$ & Height, cm & $\begin{array}{l}\text { Length of the } \\
\text { main spike, cm }\end{array}$ & $\begin{array}{l}\text { Number of } \\
\text { flowers, pcs. }\end{array}$ & $\begin{array}{l}\text { Number of } \\
\text { seeds, pcs. }\end{array}$ & $\begin{array}{l}\text { Weight of } \\
\text { seeds, } g\end{array}$ & $\begin{array}{c}\text { Weight of } \\
1000 \text { seeds, g }\end{array}$ \\
\hline \multicolumn{8}{|c|}{ Kazakhstanskaya early ripe } \\
\hline Control & $4.9 \pm 0.2$ & $89.6 \pm 1.4$ & $11.2 \pm 0.2$ & $53.9 \pm 1.9$ & $47.1 \pm 1.5$ & $1.9 \pm 0.1$ & $31.3 \pm 4.5$ \\
\hline Triton 305 & $4.6 \pm 0.2$ & $90.2 \pm 0.8$ & $10.5 \pm 0.2$ & $50.6 \pm 1.9$ & $45.8 \pm 1.7$ & $1.9 \pm 0.1$ & $33.9 \pm 2.7$ \\
\hline Triton 100 & $4.3 \pm 0.2$ & $76.4 \pm 1.4^{* * *}$ & $10.3 \pm 0.2^{* * * *}$ & $47.9 \pm 1.6^{*}$ & $41.4 \pm 1.6^{* *}$ & $1.7 \pm 0.1$ & $29.4 \pm 1.0$ \\
\hline Tween 855 & $4.7 \pm 0.3$ & $88.5 \pm 1.1$ & $11.8 \pm 0.3$ & $53.5 \pm 2.5$ & $48.9 \pm 2.5$ & $2.1 \pm 0.1$ & $38.1 \pm 2.0$ \\
\hline Tween 65 & $4.4 \pm 0.2$ & $89.1 \pm 0.6$ & $11.1 \pm 0,2$ & $56.1 \pm 1.1$ & $51 \pm 1.1$ & $2.2 \pm 0.1$ & $40.8 \pm 1.2$ \\
\hline Tween 20 & $4.0 \pm 0.2^{* * *}$ & $86.5 \pm 1.2$ & $10.9 \pm 0.2$ & $57.2 \pm 1.6$ & $51.7 \pm 1.5$ & $2.1 \pm 0.1$ & $41.9 \pm 0.1^{*}$ \\
\hline \multicolumn{8}{|c|}{ Kayir } \\
\hline Control & $3.8 \pm 0.2$ & $82.2 \pm 1.2$ & $10.9 \pm 0.3$ & $45.4 \pm 0.3$ & $40.9 \pm 1.7$ & $1.6 \pm 1.9$ & $30.7 \pm 1.0$ \\
\hline Triton 305 & $3.9 \pm 0.1$ & $79.1 \pm 1.3$ & $11.6 \pm 0.3$ & $55.7 \pm 2.2^{* *}$ & $50.4 \pm 2.1$ & $2.3 \pm 0.1$ & $30.0 \pm 2.5$ \\
\hline Triton 100 & $3.3 \pm 0.1^{*}$ & $71.2 \pm 1.3^{* * *}$ & $11.7 \pm 0.1$ & $43.5 \pm 2.3$ & $39.2 \pm 2.7$ & $1.6 \pm 0.1$ & $28.6 \pm 1.0$ \\
\hline Tween 855 & $4.6 \pm 0.2^{* * *}$ & $88.3 \pm 0.6^{* * *}$ & $12.1 \pm 0.2^{*}$ & $51.1 \pm 1.1^{* * *}$ & $47.9 \pm 1.2^{* * *}$ & $2.1 \pm 0.1$ & $36.8 \pm 1.5^{* *}$ \\
\hline Tween 65 & $3.9 \pm 0.2$ & $78.4 \pm 0.6^{* *}$ & $11.2 \pm 0.3$ & $54.1 \pm 1.8^{* *}$ & $48.7 \pm 1.9^{* * *}$ & $2.1 \pm 0.1$ & $30.1 \pm 1.8$ \\
\hline Tween 20 & $3.0 \pm 0.1^{* * *}$ & $81.4 \pm 0.8$ & $11.7 \pm 0.2$ & $53.2 \pm 2.6^{* * *}$ & $50.4 \pm 2.8^{* * *}$ & $2.2 \pm 0.2$ & $35.5 \pm 1.6^{* *}$ \\
\hline
\end{tabular}

During the study of the mutant forms of Kayir variety on the quantitative traits that define the basic elements of productivity, it is observed that in comparison with the control of the surfactant - Tween 85 has a stimulating effect, which is expressed by a significant increase in a number of indicators on the studied traits. For instance, test plants have significant increase in the length of the spike on average of $12.1 \pm 0.2 \mathrm{~cm}$, in comparison with $10.9 \pm 0.3 \mathrm{~cm}$ in control.

It is noted that the induction by surfactants Tween 85 and Tween 20 is characterized with a significant increase in the weight of 1000 seeds.

Thus, the study of the elements of productivity of mutant forms of the $M_{2}$ generation derived from local varieties of soft wheat make possible to estimate a positive stimulatory effect of surfactant Tween 20 to improve the performance of important agronomic characters, one of which is the weight of 1000 seeds [5].

\section{References}

1. Omirbekova N.Zh. Surfactants influence on soft wheat meiosis (Triticum aestivum L.) // Materials of the International conference "Fundamental and applied aspects of genetics". Minsk, 2008. - P.136-140.

2. Omirbekova N.Zh., Sankaibayeva A., Dauletbayeva S., Zhunusbayeva Zh., Chunetova Zh., Shulembayeva K.K. Influence of surfactants on soft weat (Triticum aestivum L.) mitosis // Research results. - 2009. - № 4. - P. 98-102.

3. Koishibayev M. Grain diseases. Almaty «Bastau», 2002. - P.368.

4. McIntosh R.A., Wellings C.R., Park R.F. Wheat Rusts: An atlas of Resistance Genes. CSIRO, Australia, 1995. - P.213.

Omirbekova N., Shulembaeva K.K., Zhunusbaeva Zh., Zhussupova A., Chunetova Zh., Dauletbaeva S. Use of weak mutagens in wheat breeding. HGM, 2013, Singapore. - P. 175-176. 